LEUCOTOMY AND HYPERTENSION

\section{A CASE REPORT}

BY

\author{
R. W. TIBbETTS, M.A., B.M., D.P.M. \\ (From the Psychiatric Department, St. George's Hospital, \\ S.W.1)
}

The following case raises points of theoretical and practical interest, with special reference to the psychosomatic relationships of hypertension.

\section{Case Report}

A housewife, then aged 54, was first seen in the psychiatric out-patient department of St. George's Hospital by Dr. Desmond Curran in September, 1947. The presenting symptoms were suicidal depression, intense headaches, and deterioration of vision of three years' duration. A few weeks later she was admitted under Dr. Curran's care into the St. George's Psychiatric Unit at the Atkinson Morley Hospital, Wimbledon.

She is said to have been a woman of active but even temperament. Her personal history, free as it was from abnormal stress, instability, or disharmony, contributes little to an understanding of the case. Marital relations have been good and her three children enjoy good health. Pregnancies and puerperia were uncomplicated. The family history is significant only in so far as the father was asthmatic and one of eleven siblings committed suicide at the age of 21 , in the face of considerable stress.

\section{Onset}

Her physical and mental health was good until 1944,. when her spontaneity and outside interests began to decrease. Intense stabbing supraorbital headaches were increasingly frequent and her menses became irregular. Her visual acuity was decreasing and there were multiple inconsistent symptoms of a hysterical kind. Depression, accompanied by headache and worse in the morning, became so severe that suicidal preoccupation was almost constant. Her threats completely disorganized home life, and on four occasions she made material suicidal preparations or attempts. Even making allowance for histrionic features, the underlying risk was considerable.

In 1946 she was admitted to Dorking Cottage Hospital under Dr. Brice-Smith, who, with the aid of intravenous and retrograde pyelograms and blood-urea estimations, was able to exclude a renal basis for the hypertension. At this stage she was referred to Dr. Strauss at the department of psychological medicine, St. Bartholomew's Hospital. On the organic side arteriosclerosis, hypertension, and a small retinal haemorrhage were noted, while phobias and other neurotic symptoms were prominent. Some of these were alleviated by a narcoanalysis performed by Dr. Jonathan Gould, but the depression persisted. The intractability and severity of the depression were such that certain risks were justified, and it was agreed that electric convulsion therapy should be given a trial. Seventeen treatments were given in two courses over a long period, but the slight improvements were never sustained. Due consideration being given to the operative risk with an arteriosclerotic subject, Dr. Strauss and Dr. Gould concurred that the indications were in favour of prefrontal leucotomy.

At the Atkinson Morley Hospital her blood pressure was observed closely for three weeks. At its most favourable it was of the order $170 / 100$. It was usually considerably higher and there were frequent hypertensive attacks associated with intense headache, with the blood pressure as high as $260 / 160$. Dr. Gerald Parsons-Smith reported: "This patient has severe arteriosclerosis with hypertensive heart disease. The hypertension is at present in a labile stage and has not become fixed at the high figures of $260 / 160$, which will eventually become the position. Examination of the fundi confirms the severe arterial changes. ..." Clinically there was slight cardiac enlargement and an accentuated aortic second sound. There was no papilloedema, but the retinal haemorrhage was still visible. The blood urea was $28 \mathrm{mg}$. per $100 \mathrm{ml}$. All other relevant special investigations yielded insignificant results.

From the mental standpoint she was profoundly tense and depressed and moderately retarded. She made one suicidal gesture in the ward and was constantly on full precautions. Sleep and appetite were poor. There was little self-reproach, and she was not deluded. Her recent memory, as might have been expected, was patchy, but on the whole there was nothing to indicate organic cerebral deterioration.

Treatments which had proved unavailing at various hospitals included pethidine, nicotinic acid, oestrin preparations, venesection, strong sedation, psychotherapy, and E.C.T. Sympathectomy had been considered to be contraindicated. Dr. Curran agreed that leucotomy should be recommended, and the risks were explained to her husband. Mr. Wylie McKissock generously undertook to perform the operation, and bilateral prefrontal leucotomy was performed on October 29, 1947, the approach being that described elsewhere (McKissock, 1943). Very severe arterial haemorrhage occurred on the left side, but eventually the flow was controlled with a tantalum clip.

\section{Post-operative History}

The patient's general condition in the immediate postoperative phase, while never critical, gave rise to concern for about two days. Her pulse remained regular and the blood pressure, after the initial shock, fluctuated slightly around 140/80. She was incontinent for about a week, and from the mental standpoint she was free from tension and depression, but was confused and disorientated. After three weeks she was out of bed, but still apt to be confused and to confabulate. She was cheerful, greedy, fatuous, and anergic, and was inclined, even more than most post-leucotomy patients, to huddle round the fire and radiators. On one occasion a syncopal (not epileptiform) attack occurred, and in this her blood pressure fell to $80 / 40$. A haemoglobin level of $70 \%$, which responded to iron treatment, may have been contributory. Two months after the operation her behaviour was greatly improved and she was noted as being cheerful, sociable, and helpful in the ward. Her witticisms were not always fully apt and, with a set occupational task, she proved incapable of long-sustained attention. She was eating and sleeping well and gaining weight.

The next six weeks were spent at Roffey Park Rehabilitation Centre, where, in such a favourable environment, she continued to improve, especially from the occupational standpoint. Frequently recorded blood-pressure readings were always between 160/90 and 140/80. On one occasion an epileptiform attack occurred and subsequently she received a 1-gr. (65-mg.) tablet of phenobarbitone twice a day.

Since that time the patient and her husband have been seen about every two months, the last attendance being 16 months after the operation. The following are summaries of the findings.

1. There have been no headaches worthy of note.

2. The prevailing mood is cheerful and she has been virtually free from tension or depression. The personality changes, as betrayed by occasional outspoken remarks or carefree domestic attitudes and slight limitation of foresight, are scarcely evident as such to the family. She works harder than many and the home is well run. This contrasts with her almost total social and domestic incapacity during her illness.

3. She has had three attacks of (almost certainly) minor epilepsy related to inconsistent taking of phenobarbitone. The last attack was in April, 1948.

4. Precipitancy and occasional enuresis have occurred, but there has been no enuresis in the last two months.

5. She has continued to gain weight-from about 8 st. to 12 st. (50.8 to $76.2 \mathrm{~kg}$.) - since the operation. Her friends and family claim to like her "comfortable figure," but she is definitely obese.

6. The menstrual periods have ceased entirely since' the operation. 
7. The most striking change is that the blood pressure has always been within the range $160 / 100$ to $140 / 95$. There has been no tendency for it to rise month by month.

8. She was re-examined by Dr. Parsons-Smith 15 months after the operation. He states: "There has been quite a remarkable change in this patient's general medical condition since I saw her in 1947. Recently she has had no symptoms referable to her cardiovascular state, which is all the more striking since she has gained 4 st. $(25.4 \mathrm{~kg}$.) in weight. She still has well-marked arteriosclerotic changes, but the fundus is free from exudates and haemorrhage and there is no papilloedema...."The apex beat was in the fifth space in the same position as before, $4 \frac{1}{2}$ in. $(11.4 \mathrm{~cm}$.) from the mid-sternal line, but there were no other abnormal physical signs.

9. Special Investigations (January, 1949, 15 months after operation). - Electrocardiography : - Unfortunately no preoperative record was available for comparison. Taking this into account, the record at this time was not significantly abnormal. Electroencephalography :- "The E.E.G. recorded on this date was very abnormal. The tips of both frontal lobes showed flat records, but elsewhere irregular slow waves were seen in all leads. These were occasionally organized into short rhythms characteristic of epileptic discharges." The blood urea was $25 \mathrm{mg}$. per $100 \mathrm{ml}$. A radiograph of the chest confirmed slight cardiac cnlargement, but there was no change from the pre-operative picture.

10. Mrs. Petrie, reassessing the patient eight months after the operation, reported the I.Q. as 109 (Wechsler-Bellevue scale). The gain of 10 points over the pre-operative level was largely a measure of increased co-operation.

11. The tendency to improve since the leucotomy still seems to be operative.

\section{Discussion}

There can be little doubt that without the operation the patient was faced with a future of almost constant suffering until death occurred from suicide or cardiovascular complications. The price which has been paid in personality change is familiar in quality but small in degree ; progressive hypertensive changes would probably have affected the personality more adversely.

The final cessation of the menstrual periods and the obesity (greater than one might have a right to expect in terms of energy output and food intake) point to endocrine or metabolic changes, about the exact nature of which we can only speculate. The craving for heat, which we have observed more than once after leucotomy, is interesting. It has seemed to us to have a more fundamental basis than mere anergia or hedonism, and, clinically, hypothyroidism has not been indicated. The fact that in monkeys increased heat loss has been shown to follow experimental ablation of area 13 is worth noting (Livingston, Fulton, et al., 1948). It is thought that this may possibly be due to reduction in the amount of peripheral sympathetic activity; in this context it is interesting to note that, in spite of full precautions, our patient developed a bedsore on one buttock after the operation. This has occurred in no other leucotomy patient in our experience.

The main interest in this case, however, attaches to the fall and the greatly increased stability of the blood pressure. Abrupt changes in blood pressure are commonly observed during the operation, and Freeman and Watts (1942) write: "On a number of occasions we have observed a precipitate drop in the blood pressure following incision of the subcortical white matter on one side and then an almost equally abrupt elevation, sometimes amounting to as much as 60 or 80 points, as the other side was operated upon."

In the majority of patients there is little permanent difference between the blood-pressure readings after operation and those recorded during the illness. Where, however, a high degree of nervous tension, in association with a raised blood pressure, existed before the operation, and where this tension is relaxed afterwards, there is a general tendency for the post-operative readings to remain at significantly lower levels. . The tendency for the blood pressure to fail to reach the previous high peaks after leucotomy is best seen in frankly hypertensive patients; Freeman and Watts (1942) have described two such cases. Both of these women were suffering from agitated depression, and the relevant facts were:

\begin{tabular}{l|c|c}
\hline & B.P. Before Leucotomy & B.P. After Leucotomy \\
\hline $\begin{array}{l}\text { Case A (aged 59) } \\
\text { Case B (aged 66) }\end{array}$ & $\begin{array}{c}184 / 110-222 / 128 \\
\text { Around 220/110 }\end{array}$ & $\begin{array}{l}190 / 105-195 / 110 \text { (3-year follow-up) } \\
130 / 70-155 / 80 \text { in hospital, and round } \\
195 / 75 \text { with full activity }\end{array}$ \\
\hline
\end{tabular}

The findings in both these cases are comparable with but less pronounced than those in the case reported above.

Three theoretical possibilities suggest themselves as explanations for the sustained reduction and the increased stability of blood pressure:

(a) Decreased physical activity after operation. This is not borne out by our patient, whose pre-operative readings were taken in bed.

(b) That the changes are due to interference with localized anatomical areas particularly concerned with automatic function. Evidence, largely inspired by the work of Fulton in America, points particularly to area 13 , and to a less extent to area 14 (Stanley and Jaynes, 1949) on the orbital surface of the frontal lobe ; the rostral part of the cingulate gyrus (area 24) is also suspect. While these areas are usually avoided in the performance of prefrontal leucotomy they have at times been involved.

Smith (1945), in stimulating the rostral part of the cingulate gyrus in monkeys, produced, among other changes, a significant rise in blood pressure without alteration in the cardiac rate. Ward (1948) described personality changes in the monkey after ablation of this area, and these changes are in some ways comparable to those which may be seen in man after leucotomy. Attention, however, has centred mainly on the orbital surface of the frontal lobe.

Changes in blood pressure (usually a rise), together with inhibition of respiration and decrease in gastric tonus, have been produced in animals by stimulating an area near the olfactory tract (Bailey and Sweet, 1940 ; Delgado and Livingston, 1948). In the monkey the blood-pressure responses are still operative if the vagi are cut and adrenals removed (Livingston, Fulton, et al., 1948). More recently experiments have been carried out (Livingston, Chapman, and Livingston, 1948) in which, under moderate thiopentone anaesthesia, the orbital surfaces of leucotomy patients were stimulated before the operation. A gradual but consistent and significant rise in blood pressure followed stimulation, and it was shown that this was not causally related to the inhibition of respiration, which also occurred.

It is worth noting that in our patient none of the hyperactivity described in monkeys in relation to lesions of area 13 was seen (Livingston, Fulton, et al., 1948; Ruch and Shenkin, 1943); hyperphagia, however, was certainly evident at first. The whole issue is of course obscured by our inexact knowledge of the extent of the lesion; in view of the haemorrhage this may have been considerable.

(c) The third approach assumes a close relationship between the mental tension and the raised blood pressure, so that a decrease in the one is accompanied pari passu by a fall in the other. This seems probable on general grounds and in view of the fall in blood pressure sometimes seen after patients who are both hypertensive and depressed have received electric convulsion treatment. In our present state of knowledge we are at a loss to know whether to think in terms of pressor substances or thalamo-frontal radiations, or a combination of the two. 
In the selection of the small group of similar cases which might be helped by leucotomy the following criteria are suggested tentatively: (1) The mental state should be such as to call for leucotomy irrespective of the hypertension, and the mental tension should be pathologically high. (2) Every reasonable form of alternative treatment should have been tried without sustained response. (3) The outlook without leucotomy should be bad enough to make all concerned prepared to face a considerable operative risk. (4) Intellectual deterioration should be negligible. (5) The hypertension should be labile, as determined, if necessary, by the intravenous injection of sodium amytal. The arteries should preferably be in a healthier state than in the above case and there should never have been any indication of heart failure. (6) The renal function should be completely satisfactory.

\section{Summary}

A case is reported of prefrontal leucotomy performed on a hypertensive patient suffering from severe and intractable depression, the onset of which was associated with the climacteric.

Blood-pressure readings previously ranging between $170 / 100$ and $260 / 160$ have over the 16 months since the operation remained stabilized between $140 / 95$ and $160 / 100$. A retinal haemorrhage seen before the operation is no longer evident.

Possible explanations for these findings and for others which may be related to autonomic functions are discussed.

The disappearance of symptoms and the very great improvement in the domestic situation are considered to outweigh the personality changes and other complications.

Suggestions are made concerning the indications for performing prefrontal leucotomy where hypertension is one of the factors.

I am indebted to all those mentioned in the text for their help and more particularly to Dr. Desmond Curran for criticism and encouragement and to Dr. Hazel Liddell for the use of her original notes on the case.

\section{REFERENCES}

Bailey, P., and Sweet, W. H. (1940). J. Neurophysiol., 3, 276. Delgado, J. M. R., and Livingston, R. B. (1948). Ibid., 11, 39. Freeman, W., and Watts, J. W. (1942). Psychosurgery. Springfield Illinois.

Livingston, R. B., Chapman, W. P., and Livingston, K. E. (1948) Res. Publ. Ass: Nerv. ment. Dis., 27, 421.

Fulton, J. F., Delgado, J. M. R., Sachs, E., Brendler, S. J., and Davis, G.'D. (1948). Ibid., 27, 405.

McKissock, Wylie (1943). J. ment. Sci., 89, 194.

Ruch, T. C., and Shenkin, H. A. (1943). J. Neurophysiol., 6, 349. Smith, Wilbur K. (1945). Ibid., 8, 241.

Stanley, W. C., and Jaynes, J.'(1949). Psychol. Rev., 56, 18.

Ward, Arthur, A., jun. (1948). Res. Publ. Ass. Nerv. ment. Dis., $27,438$.

Speaking at a conference on home helps recently, Dr. Peters, Deputy Chief Medical Officer, Department of Health for Scotland, said that though the hospital and specialist services might be the most costly and the most spectacular part of the National Health Service a great deal of its work would be stultified if it could not be followed by continued care in the home. Sociomedical services were of the utmost value in helping to keep the family together and preventing it from being broken up, as it so often could be, by the sickness or disability of one of the parents or bread-winners. The home help should be looked on as a member of a team, along with the family doctor, the health visitor and the district nurse, which could do a great deal towards alleviating suffering and anxiety. She was not a nurse, although occasionally her duties might have to extend to some personal attention, but she was a trained member of a team of social workers whose job it was to help and strengthen the home. Some authorities were already reporting remarkable success in their efforts to supply home helps. The home-help arrangements could be one of the most important and most rewarding parts of the whole National Health Service.

\section{Medical Memorandum}

\section{A Shot-filled Appendix}

Many cases of appendicitis have been found to contain lead shot inside the lumen of the appendix; usually two, three, or four pieces are discovered. The following case is unusual because of the large number of shot found.

\section{CASE Report}

The patient, an unmarried woman aged 52, had a threemonths history of vague abdominal symptoms which were becoming progressively worse. These symptoms consisted of pain in the epigastrium and in the right lower quadrant of the abdomen, flatulence, attacks of nausea, and, very occasionally, vomiting. The pain was in no way related to meals. There was no loss of weight and there had been no previous similar history. Associated with the abdominal symptoms was

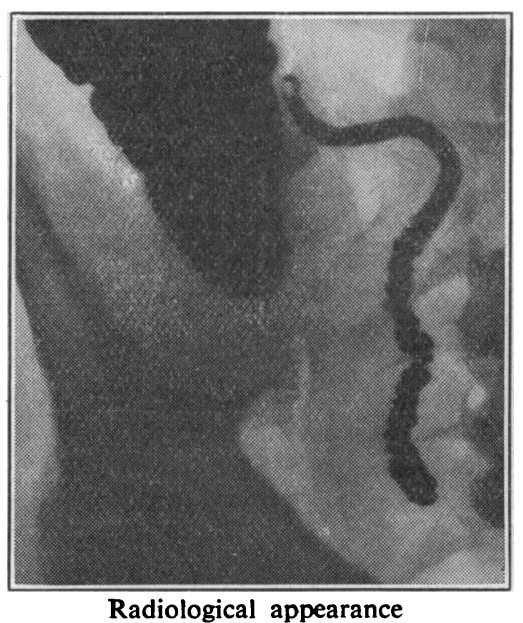

shoulders for about the same length of time.

Clinical examination revealed a well-built patient with a marked absence of signs except for tenderness in the epigastrium and right iliac fossa, in neither of which was it very severe. In view of her age and the vagueness of the symptoms and signs a cholecystographic and barium meal examination was made.

The radiological report (Dr. S. Cochrane Shanks) stated: "The cholecystogram was normal, the stomach and duodenum showed a coarse mucosal pattern consistent with a gastroduodenitis, but there was no sign of actual ulceration. The appendix was very long, and was filled in its distal half with what appeared to be lead shot. There was tenderness over the appendicular shadow. Doubtless the length of the appendix had something to do with the stasis in the distal half."

The case was referred to a consulting surgeon, Mr. Michael J. Smyth, F.R.C.S., who performed a laparotomy, with a paramedian incision extending from the umbilicus downwards. No abnormality was found except that the appendix was distended and bulbous, and was removed. The patient made a rapid and uneventful recovery, all her symptoms, including the head and neck pains, having disappeared.

A pathological examination of the appendix was made by Dr. E. Cuthbert Dukes, who reported as follows: "The appendix was enlarged and its wall was thickened. Its interior was packed with more than 60 small lead shots. No other abnormality was seen. Microscopical examination showed only a slight increase in fibrous tissue in the submucosa. In all other respects the histology was normal." (See photograph.)

It was later discovered that the patient often ate game, her brother being a first-class shot.
C. Eppei, M.B., B.Ch. 